\title{
Interweaving mathematics with reality and beauty: the valuable legacy of Emma Castelnuovo
}

\author{
Franco Lorenzoni
}

Published online: 19 August 2014

(c) Centro P.RI.ST.EM, Università Commerciale Luigi Bocconi 2014

\begin{abstract}
The great lesson about education that Emma Castelnuovo left us lies in imagining a living mathematics in which youngsters can recognise themselves, because it is tied to reality and beauty. The interweaving of mathematics and art, between mathematics, architecture and life, together with a constant reference to history, makes it possible for students to think of mathematics as a body of knowledge that is dynamic and open to the future. Emma Castelnuovo was a master at using educational materials to facilitate the approach to complex mathematical and geometrical concepts, manipulating figures in transformation and creating active, effective relationships between hands, eyes and brain. To do this it is necessary to dedicate a great amount of time to talk with and listen to the students' hypotheses, allowing them 'time to lose time'. Finally, offering important topics, such as the infinite and infinitesimal, allows youngsters to engage in a healthy head-tohead struggle for knowledge.
\end{abstract}

Keywords Emma Castelnuovo - Mathematics teaching · Mathematics learning - Educational materials · History of mathematics

Shortly after her one-hundredth birthday, Emma Castelnuovo passed away, in April 2014. A tireless innovator, I have never saw her sit down for a single instant during the 3 years of middle school when I had the good fortune to have her as a teacher (Fig. 1).

Agile in body and in thought, while still very young she found herself teaching in the teacher training courses of the

F. Lorenzoni $(\square)$

Cenci casa-laboratorio, Strada di Luchiano 10, 05022 Amelia, Terni, Italy

e-mail: cencicasalab@gmail.com
Jewish school in Rome because, just after she had won the competitive examination, she was barred from teaching in Italian schools because she was Jewish. This was in 1938, and the Roman Jews reacted to that abuse of power with great determination, establishing in a few short months a Jewish school where Emma, daughter of the mathematician Guido Castelnuovo, was called to teach the teacher training classes. Becoming aware that the program for mathematics did not respond to the needs of the students, she participated - at the height of the war-in the intense research work of a small group that met regularly at the home of Federigo Enriques, her uncle, who was a mathematician and a historian of science of high calibre. Founder of the Italian Philosophical Society, Enriques was violently opposed by Benedetto Croce who, in 1911, spoke arrogantly about 'this professor of mathematics who dabbles in philosophy'. We Italians know quite well how that cultural conflict ended, because Italian schools are still today permeated with a culture that takes a very simplistic view of the role of science and mathematics, which are generally kept far removed and distinct from philosophy, art and letters.

Negating the best traditions of the Italian Renaissance, which saw an extraordinary interweaving between anatomy and sculpture, and between painting, architecture and geometry, idealism imposed on the school that rigid hierarchy of knowledge that even today permits many intellectuals to claim to not understand anything about mathematics, as if this branch of knowledge were not rich in creativity, speculative daring, and the capacity to understand and interpret the world.

The outcome of that battle contradicted what Guido Castelnuovo, with farsightedness, had stated years earlier, in Genoa in 1912, in a lecture given to third congress of the 


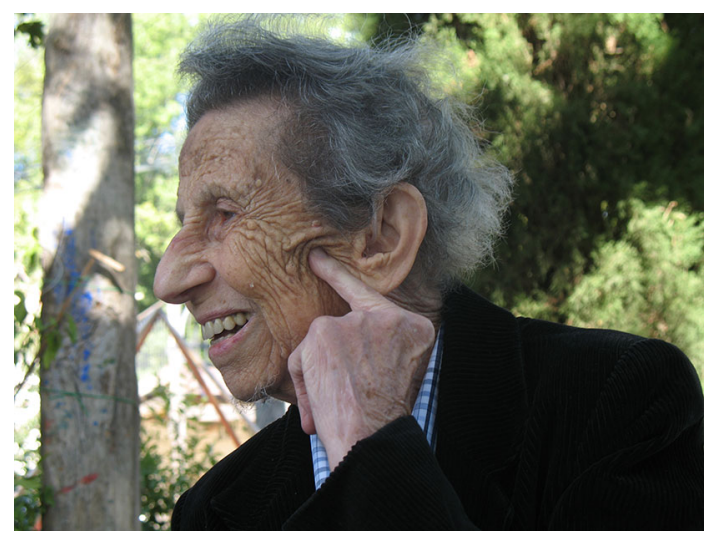

Fig. 1 Emma Castelnuovo

Mathesis Association, an association for mathematics teachers:

... this is the chief wrong of the doctrinaire spirit that invades our schools. There we teach [students] to be wary of the approximate, which is reality, to worship the idol of a perfection that is illusory. There we represent the universe as an edifice, whose lines have a geometric perfection and appear to us as defaced and clouded because of the coarse nature of our senses, while we should make it understood that the uncertain forms revealed to us by the senses constitute the only accessible reality, which we substitute, to respond to certain needs of our spirit, with an ideal precision [5, p. 18 (our trans.)].

Many years later, following in the footsteps of her father, she reprised his words, adding:

They will say that it is impossible to give a child a certain idea of function, that it is dangerous to speak of the concept of limit in vague terms, they will say that when you teach it must be perfect in order not to give rise to wrong ideas, which will then be difficult to eradicate in order to replace them with appropriate definitions. When I hear these objections I am reminded of what Guido Castelnuovo wrote about this: 'That which we know by the professor or by the student-I was told -, limited though it be, must still must be known perfectly. Now, I am a mild and tolerant spirit, but every time someone objects to me with this phrase, an evil thought flashes across my mind. Oh, if I could take my interlocutor at his word, and with a magical power switch off for a moment in his brain all the vague knowledge, allowing to persist only what he knows! You can't imagine what a miserable spectacle I would present to you! Even admitting that after such a cruel mutilation there might still remain some glimmer in his intellect, which I strongly doubt, it would look like a flickering flame lost in deep and boundless darkness. The truth is that we know nothing perfectly [2, p. 157 (our trans.)].

Strongly marked by the profound convictions of her father, and critical of any doctrinaire spirit, Emma Castelnuovo found the programs and textbooks in use in middle schools, where she was rehired and began to teach as soon as the war was over, to be absurd. In fact after just 4 years, she gathered her courage and wrote La geometria intuitiva per la Scuola Media (Intuitive Geometry for Middle School) [1], a book that turned mathematics teaching inside out like a sock. The point of departure was no longer the postulates and abstract definitions of points, lines and figures, but the observation of reality and of a geometry that Emma Castelnuovo had the brilliant idea of putting immediately into action.

That 'crazy book', as she called it in her later days, led to an invitation to become a member, beginning in 1951, of the Commission Internationale pour l'Etude et l'Amélioration de l'Enseignement des Mathématiques (CIEAEM, the International Commission for the Study and Improvement of Mathematics Teaching), founded by mathematician Gustave Choquet, psychologist Jean Piaget, and mathematician, psychologist and pedagogue Caleb Gattegno.

Using string, rubber bands and pieces from Meccano sets, we students, in the classroom, were invited to construct geometric figures that we could manipulate with our hands. Those constructions generated questions, led us to formulate hypotheses for experimentation, and began to move, along with our hands, our thoughts and reasoning.

Emma Castelnuovo always maintained that hands are the most democratic tools, because from constructing in a group you learn to reason together, working with concrete figures whose shapes change in front of our eyes. In that way many mathematic passages, irksome for those who are less skilful in abstraction, could be understood by everyone.

Yes, because what was most important to Emma Castelnuovo was not only to enliven and render fascinating the pathways of mathematical knowledge, but also to devise tools that could make it accessible to all.

A curious world traveller, always on the lookout for new ideas to work with, on her return from one of the many international congresses that she was invited to take part in, the young Emma decided to stop over in Geneva to try to meet Jean Piaget, who was engaged in those years in his research on the development of thought in children. 'Speak to him about angles and he is sure to receive you', she was told by his assistant over the phone. In fact, the next day she found herself with the great Swiss psychologist, talking 
about angles, which are not so easy for youngsters to understand, because 'they contain the infinite'. Today the most discerning teachers know quite well that the body in motion, open eyes, and the use of materials are an enormous aid to the acquisitions of mathematical knowledge, but in the 1950s all of this was just at the beginning, except for some intuitive ideas of Ovide Decroly, Maria Montessori, and earlier, Friedrich Fröbel.

Indeed, it wasn't until 1957 that the first international congress for mathematics teaching was held in Madrid, dedicated entirely to the use of materials in teaching.

Archimedes versus Euclid we might say, playing with our predecessors, also because Emma Castelnuovo always had a particular love for the mathematician from Syracuse, who had an extraordinarily effective way of uniting physical observations with mathematical considerations, as did Galileo later. This leads us to another of Emma Castelnuovo's warhorses: always making a connection between discoveries and theorems and their history, so that youngsters could understand that mathematics is a living subject, where it is still possible to make discoveries.

Still today, when I see the rays of sunlight come in through a window and fall on the floor, I cannot help but thinking of what Emma had us observe in class, that is, that those parallelograms of light in constant motion tell about the properties of affinity better than any book can. Yes, because Emma, even before she had us study geometry, had us look at and touch with our own hands the figures in motion and their transformation. Manipulating the famous string with her fingers, for example, she asked us if the different rectangles with the same perimeter that we saw her make all had the same area. And thus two key concepts of her teaching arrived to us: the limit case, and reductio ad absurdum reasoning. In fact, if I lengthen the base while shortening the sides until they arrive at zero, I will have a rectangle of area zero, and it is precisely this 'non-rectangle' that that helps me to understand the transformations of the areas in isoperimetric rectangles.

Ad absurdum reasoning thus leads to concrete results. On the other hand, wasn't it by a kind of reductio ad absurdum that Gandhi imagined defeating the British Empire with his non-violence, and that Mandela built a nation and made peace with his former persecutors? Mathematics is much closer to us than you might believe, even in the possibility to conceive a logic capable of imagining what can't yet be seen. This is always done, however, beginning with the reality with which mathematics is interwoven and by a discerning use of materials.

It is necessary in any case, 'to give youngsters the time to lose time', that is, the possibility to dwell on things:

In mathematical discovery imagination is united with logic [and I want] to solicit the reader to ask himself

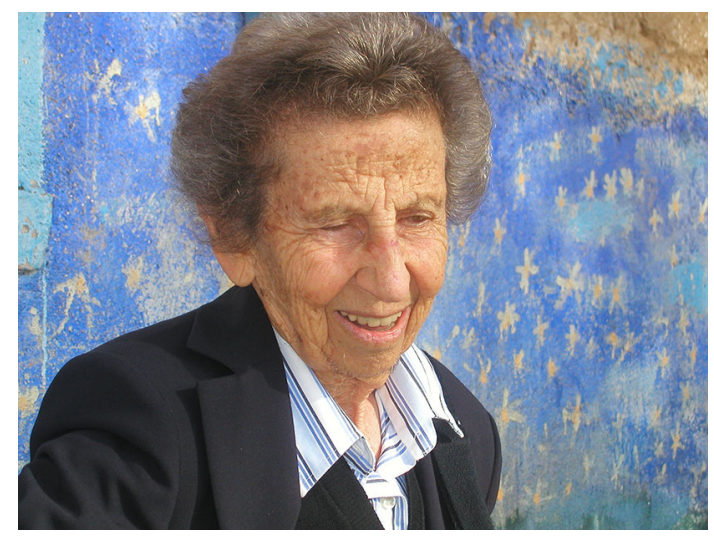

Fig. 2 Emma Castelnuovo, in Cenci during the activities of 'Officina matematica'

questions, to fall into error and then become aware of the error, in short, to take an active part in the reading almost as though he were a researcher [3, Prefazione].

It is important to note and spread the word that $\mathrm{La}$ matematica [4], her six-volume textbook for the first years of secondary school, is now available in a new edition containing the computer supports that are required today. At the age of ninety, she personally revised this very rich and pertinent educational tool, so that her extraordinary research would not be dispersed. However, it should be added that even though it appears in the catalogue of the publisher Nuova Italia, it is almost an interloper in schools today, perhaps because it is believed to be 'difficult' to use in the classroom, and because it requires teachers to put themselves on the line, radically modifying teaching. This was one of the reasons that, in 2002, Emma founded her 'Officina matematica', a mathematics workshop where each year teachers from all over Italy come together in Umbria to actively experience her materials and method. 'Officina matematica' takes place in the "Casa-laboratorio di Cenci" in Amelia, a place for educational and artistic research on themes of ecology, science, intercultural relations, and inclusion (Fig. 2).

Everyone knows how important a broad cultural background is for schools, and yet how little is invested in teacher training. In the face of the disappointing results regarding the quality of mathematical learning in our schools, going back to read the books by Emma Castelnuovo might help youngsters find anew that connection with nature, art, architecture and beauty that could contribute so much to their falling in love with mathematics, a discipline that, unfortunately, is often taught in a way that is cold, keeping it far removed from reality.

A few years ago I asked Emma what topics she liked best to present to youngsters, who were often accused of superficiality. She thought for a moment and then 
answered, the infinite and infinitesimal. Might it be that we as teachers are afraid to offer youngsters topics that are important and full of meaning, with which to engage in a healthy head-to-head struggle for knowledge?

It will be very difficult indeed for someone to carry on the legacy of this extraordinary woman, who was capable of radically overturning mathematics teaching. But if we truly care about the development of the minds of our youngsters, it is necessary to go back to studying her books, which like the great classics, never cease to pose questions for us.

Translated from the Italian by Kim Williams.

\section{References}

1. Castelnouvo, E.: La geometria intuitiva per la Scuola Media. La Nuova Italia Editrice, Florence (1949)

2. Castelnouvo, E.: Didattica della Matematica. La Nuova Italia Editrice, Florence (1963)

3. Castelnouvo, E.: Pentole, ombre, formiche. La Nuova Italia Editrice, Florence (1993)

4. Castelnuovo, E.: La Matematica. 6 vols. with a teacher's guide: Figure piane A, Figure piane B, Figure Solide, Numeri A, Numeri B, Leggi Matematiche. Firenze: La Nuova Italia. (1998)
5. Castelnuovo, G.: La scuola nei rapporti con la vita e la scienza moderna. Atti del III Congresso della Mathesis, Genoa, 21-24 Oct 1912, pp. 15-21. Cooperativa Tipografica Manuzio, Rome (1913)

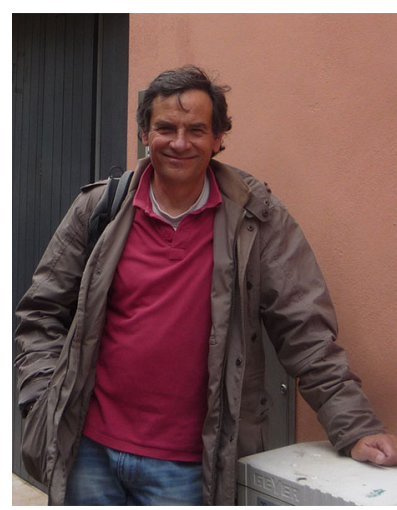

Franco Lorenzoni teaches in the elementary school in Giove, in Umbria, Italy. In 1980, together with others, he founded the "Casa-laboratorio di Cenci" in Amelia, a place for educational and artistic research on themes of ecology, science, intercultural relations, and inclusion. In 2011 this activity earned him the Premio Lo Straniero awarded during the Santarcangelo International Festival of Theatre. Active in the Movement of Educational Cooperation, he has participated in projects for international cooperation in Guatemala, Colombia and Brazil. He is that author of several books, the most recent of which is $I$ bambini pensano grande (Sellerio 2014). He is a member of the editorial boards for several magazines and journals. In 2013 he was named to the National Scientific Committee for the 'Nuove Indicazioni', the guidelines for the curriculum of pre-schools and primary schools in Italy. 